\title{
Does Colour Affect Mood - A Survey Among College Students
}

\author{
Obuli Ganesh Kishore.S1, Vishnu Priya.V² and Gayathri . R ${ }^{3}$ \\ ${ }^{1}$ Saveetha Dental College and Hospitals, Saveetha Institute of Medical and \\ Technical Sciences (SIMATS), Saveetha University, Chennai- 77, India \\ ${ }^{2}$ Department of Biochemistry Saveetha Dental College and Hospitals \\ Saveetha Institute of Medical \& Technical Sciences ( SIMATS ) \\ Saveetha University Chennai-600077, India \\ ${ }^{3}$ Department of Biochemistry Saveetha Dental College and Hospitals Saveetha Institute of \\ Medical \&t Technical Sciences (SIMATS) Saveetha University Chennai-600077, India
}

\section{ABSTRACT}

Colour is something everyone visualises everyday, it is the basic component of everything we see. When psychologically considered colours are said have an effect on one's behaviour.Colour is also an effective tool for communications. It is known that various colours denote various meanings,religiously and socially. Everyday we come across various colours. Each colour is said to have specific psychological properties.This study was conducted among college students to assess if colour had inverse effects on their daily behaviour. Survey population included 184 college students. A self structured questionnaire was circulated online.The results obtained were analysed and it was found that colour has an effect on one's day to day behaviour.

KEY WORDS: COLOUR, PSYCHOLOGY, MOOD, WAVELENGTH, HAPPY, SAD.

\section{INTRODUCTION}

Colour can be defined as the property of light,seen by people.It is said that colours could be used as a powerful tool for communication.Not only that ,but colour can also influence one's physiological and psychological reactions.It has also been medically proven that colours have influence over blood pressure,metabolism etc.We see colours with our brains. The occipital lobe of our brain is responsible for visual information of colour.

\section{ARTICLE INFORMATION}

${ }^{*}$ Corresponding Author: vishnupriya@saveetha.com

Received 28th July 2020 Accepted after revision 21st Sep 2020

Print ISSN: 0974-6455 Online ISSN: 2321-4007 CODEN: BBRCBA

Thomson Reuters ISI Web of Science Clarivate Analytics USA and Crossref Indexed Journal

\section{Clarivate
Analytics}

NAAS Journal Score 2020 (4.31) SJIF: 2020 (7.728)

A Society of Science and Nature Publication,

Bhopal India 2020. All rights reserved.

Online Contents Available at: http//www.bbrc.in/

Doi: $h t t p: / / d x$.doi.org/10.21786/bbrc/13.8/166
Human eyes visible wavelength ranges from 350nm to $750 \mathrm{~nm}$.In the eye the cones and rods are responsible for photo reception.Almost everything we see in our day today life has has colours.We live in a world filled with colours.According to various researches , the environment in which we live and the colours present around us can influence our psychological behaviour.Use of colours in treatment of mood disorders or nervous disturbances is known as chromotherapy.Hence it is evident that colours could play a vital role in a person's day today life.

Several ancient cultures, including the Egyptians and Chinese, practiced chromotherapy, or the use of colors to heal. Chromotherapy is sometimes referred to as light therapy or colorology.It is also found that different colours triggered different psychological emotions (Cherry, no date).From beverages to consumer electronics, marketers are using color in innovative ways. Despite this, little academic research has investigated the role 
that color plays in marketing (Labrecque and Milne, 2012).Even with an affinity for nature, it has become increasingly important to realize that individuals exist within enclosed structures for most of their lives. Therefore, understanding how spaces affect individuals is necessary for personal well-being (Kwallek, Lewis and Robbins, 1988).The development of color vision in primates was shaped by adaptation to selection pressures that were part and parcel of a visually complex natural environment. Critical behaviors such as wayfinding, foraging for food, and recognizing predator and prey, or friend and foe, must have played a vital role in the evolution of trichromatic color vision. An evolu-tionary advantage could have accrued if color had facili-tated natural scene recognition by enhancing encoding and recognition(Spence et al., 2006).Colours have found place also in cultural beliefs all over the world (Adams and Osgood, 1973).

Black is viewed as the color of evil and death in virtually all cultures. With this association in mind, we were interested in whether a cue as subtle as the color of a person's clothing might have a significant impact on his or her behavior (Frank and Gilovich, 1988).Hence, using the appropriate color in design is important in such buildings. It is also significant to draw cognitive maps and wayfinding in interiors. Environmental interventions that promote way finding can be implemented on two levels: the design of the floor plan typology and environmental cues, which comprise signage, furnishings, lighting, colors, and so on (Kurt and Osueke, 2014).In summary, different colors might influence students' affective states, which have impact on their workload, and in turn degenerate their performance (Kumar, Sterkenburg and Diekfuss, no date). The main aim of this study is to assess and analyse the effect of colours on moods of college students.

\section{MATERIAL AND METHODS}

A self administered questionnaire was framed based on the effect of colour on mood among college students. The questionnaire was distributed through an online 'Survey Planet' link. The study population included 184 college students. The participants were explained about the purpose of study in detail.The questions were carefully studied and corresponding answers were marked by the participants. The data was collected and statistically analysed.The results were obtained in the form of a pie chart.

\section{RESULTS AND DISCUSSION}

The data was collected and statistically analysed. From fig 1 , it was evident that only $86 \%$ of the population (153 students) were aware that colour affects mood and the rest 14\% (25 students) were unaware of it. From Fig2, it was observed that $94.4 \%$ population (169 students) were aware of various colours and the rest were not aware of all the colours. Fig 3 represents the choice of favourite colour among the students. It was seen that blue,black,red and green are the most preferred and favourite colour by most of the students.From previous studies it was found that blue was the most favourite colour among most of the students. A total of 136 students opted the colour blue among a total population of 490 students (Kurt and Osueke, 2014). From Fig4, it was known that only 24.9\% population choose the colour of their dress based on their mood, the rest does not follow that or some occasionally follow that. Fig 5 shows that every student on an average has 4 to 5 favourite colours. From Fig 6, it was evident that favourite colours did not change frequently among $57.7 \%$ population.

Figure 1: Pie chart depicts percentage distribution of responses on awareness about colour and its effect on mood. 86\% are aware (blue) and 14\% are unaware (red).

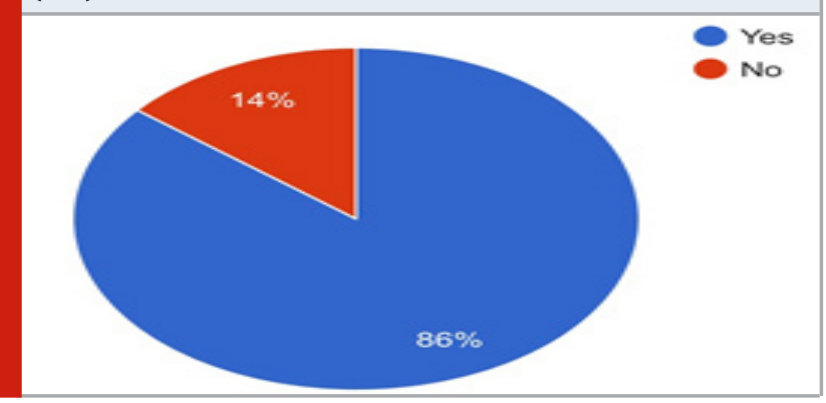

Figure 2: Pie chart depicts percentage distribution of responses on awareness about presence of various colours. 94.4\% are aware (blue) and 5.6\% are unaware (red).

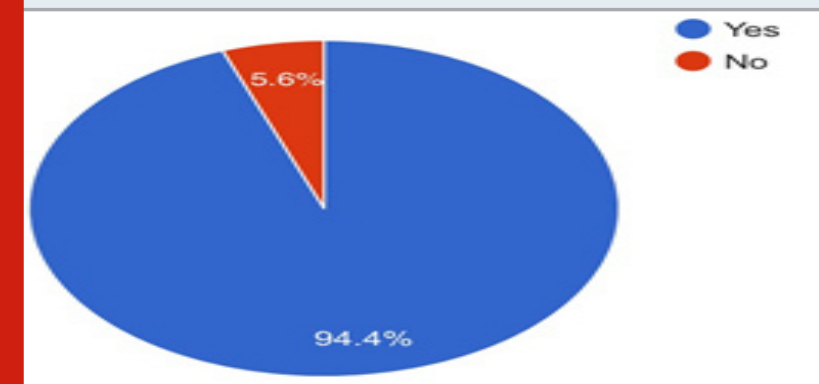

Figure 3: Pie chart depicts percentage distribution of responses on favourite colour of participants. Blue 33.9\% ( blue), Black 17.8\% (red), Red 15\% (yellow), Green 12.8\% (green), Pink 4.5\% (purple), Orange 4\% (teal), White 4\% (pink), Violet 4\% (light green), and Yellow 4\% (maroon).

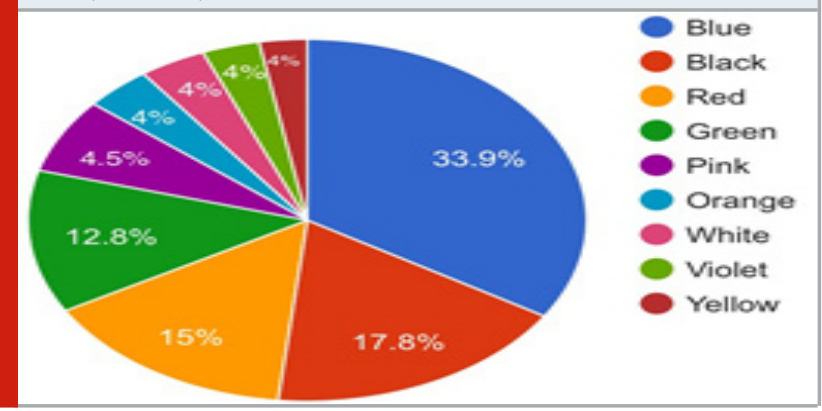


Figure 4: Pie chart depicts percentage distribution of responses on whether the participants choose the colour of the dress to wear based on their mood. $24.9 \%$ say yes (blue), 37.9\% say no (red) and 37.3\% do it occasionally (yellow).

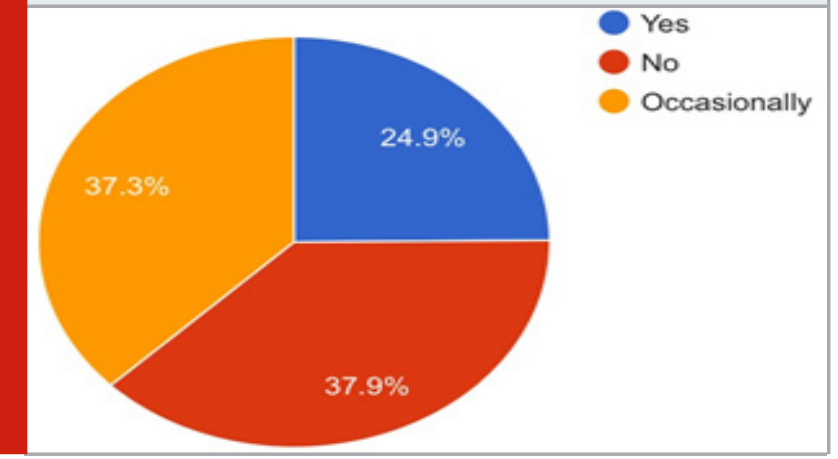

Figure 5: Scalar representation of how many favourite colours the participants have. On an average everyone has 4 favourite colours.

How many fawourite colours do you have?

Q5 Sole

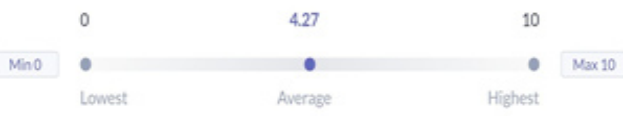

Figure 6: Pie chart depicts percentage distribution of responses on frequency of change in favourite colour. $11.4 \%$ change it frequently (blue), 57.7 do not change it (red) and 30.9\% do not change it very frequently (yellow).

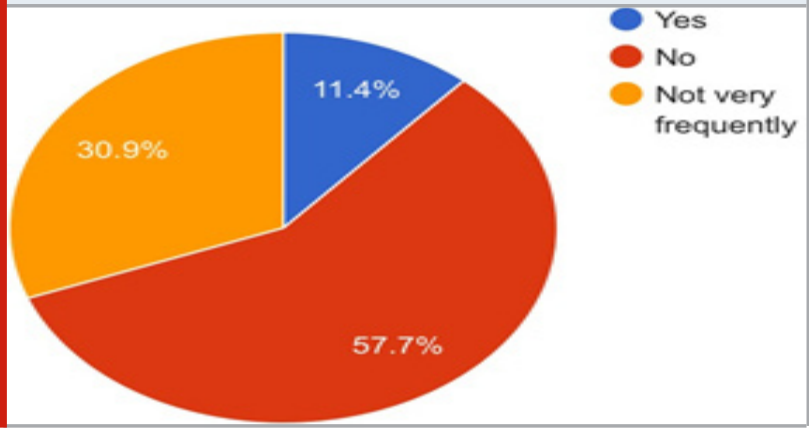

The rest 30.9\% say that it doesn't change frequently and for $11.4 \%$ population it does change.Fig 7 , the frequency of preference of buying products based on the favourite colour.It is seen that $64.4 \%$ prefer buying their favourite colours and the rest 35.6\% say it doesn't matter.From fig8, it is understood that only $45 \%$ of the students wear colours to denote something special and the rest do not practice it.From fig 9, 54.4\% of the population say that wearing their favourite colour energises them and for
$33.9 \%$ it does sometimes and for $11.7 \%$ of the population it never does.From fig 10, it is assessed that certain colours sometime causes depression in $17.3 \%$ of the population, and $57.5 \%$ disagree to that also it sometimes causes depression in $25.1 \%$ of the population.

Figure 7: Pie chart depicts percentage distribution of responses on whether the participants purchase products in their favourite colours only. 35.6\% say yes (blue) and $64.4 \%$ say no (red).

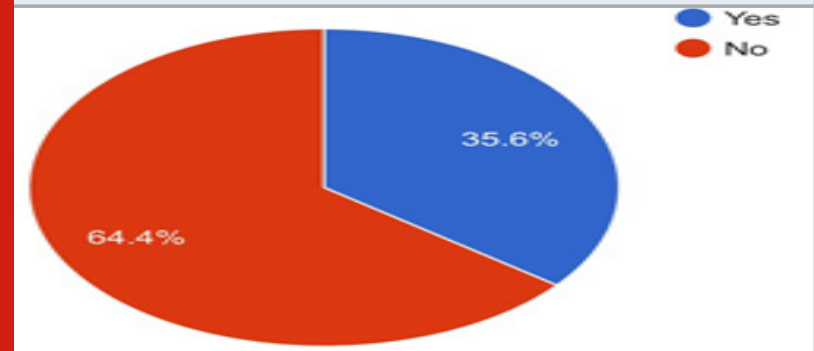

Figure 8: Pie chart depicts percentage distribution of responses on whether the participants wear colours to denote something special. 45\% say yes (blue) and 55\% say no (red).

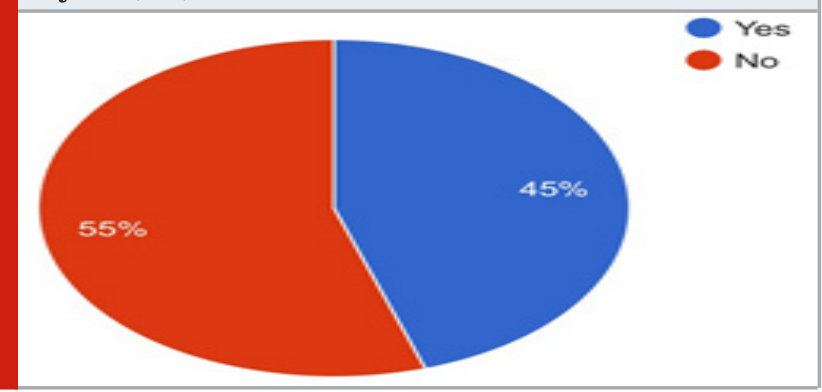

Figure 9: Pie chart depicts percentage distribution of responses on whether the participants get energised by wearing their favourite colours. $54.4 \%$ say yes (blue), $11.7 \%$ say no (red) and $3.9 \%$ say sometimes (orange).

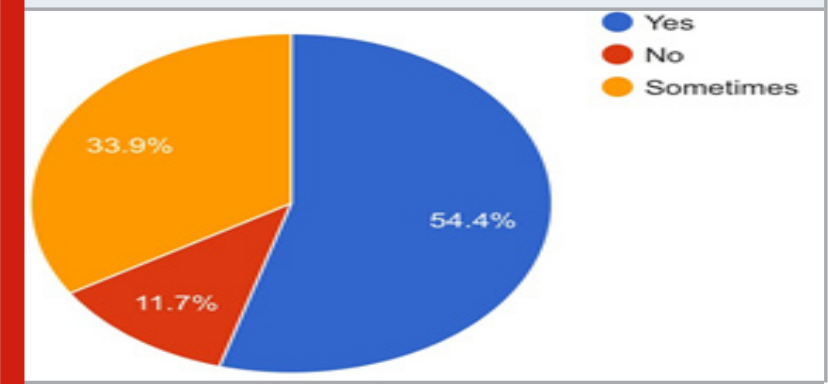

It is seen that only $62.6 \%$ of the population are aware of happy and sad colours whereas $37.4 \%$ of the population are unaware from fig 11 . From fig 12 , it is evident that $65.4 \%$ of the the population's mindset is always being happy and only $10.6 \%$ feel sad most of the time.It is seen that $82.7 \%$ of the population feel happy when they look at their favourite colour and only 5\% feel sad from fig 13.From fig 14, it is evident that bright colours cheered up $80.3 \%$ of the population and $19.7 \%$ disagreed to that. From a previous study which was conducted 326 students 
among 490 students claimed that their excitement level increased as they approached a particular place due to the colours used there(Frank and Gilovich, 1988).Almost $77.3 \%$ of the students think that different colours affect moods in different situations and $22.7 \%$ disagreed to it from fig 15 .

Figure 10: Pie chart depicts percentage distribution of responses on whether the participants get depressed by any colour. $17.3 \%$ say yes (blue), $57.5 \%$ say no (red) and $25.1 \%$ say sometimes (orange).

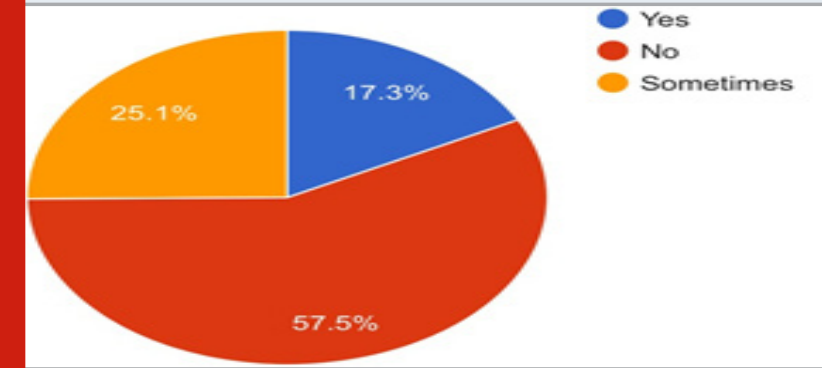

Figure 11: Pie chart depicts percentage distribution of responses on awareness about happy and sad colours. $62.6 \%$ are aware (blue) and $37.4 \%$ are unaware (red).

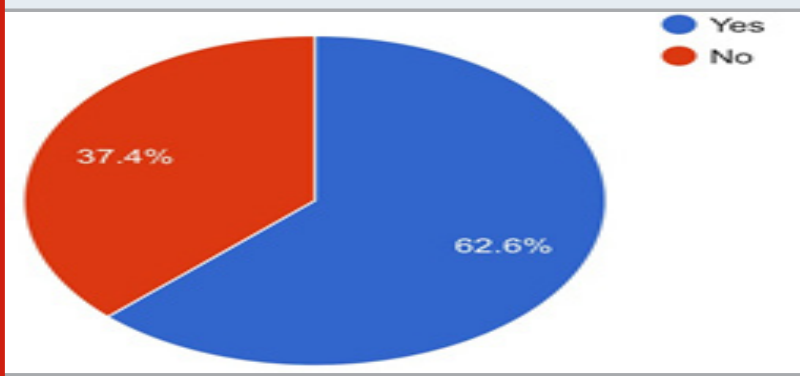

Figure 12: Pie chart depicts percentage distribution of responses on the mood of participants most of the time.65.4\% say happy (blue), 10.6\% saysad (red), 5.6\% say angry (orange) and $18.4 \%$ say anxious (green).

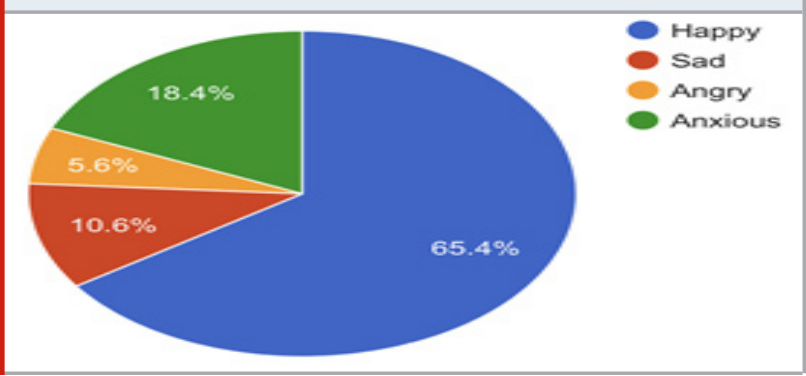

From fig 16 , it is seen that only $45 \%$ prefer wearing their favourite colours when they are happy and the rest don't.From fig 17, it is evident that $70.1 \%$ are aware that different colours denote different things and 29.9\% are unaware of it.From fig 18 , it is seen that only $30.3 \%$ students had the habit of wearing specific colours on specific days and the rest didn't have that habit.It is seen that wearing their favourite colour improved the day today activities for $53.4 \%$ of the students and the rest didn't find any adverse effects from fig 19.
Figure 13: Pie chart depicts percentage distribution of responses on the mood of participants upon visualising their favourite colour. 82.7 say happy (blue), 5\% say sad (red), 12.3\% say no effect (orange).

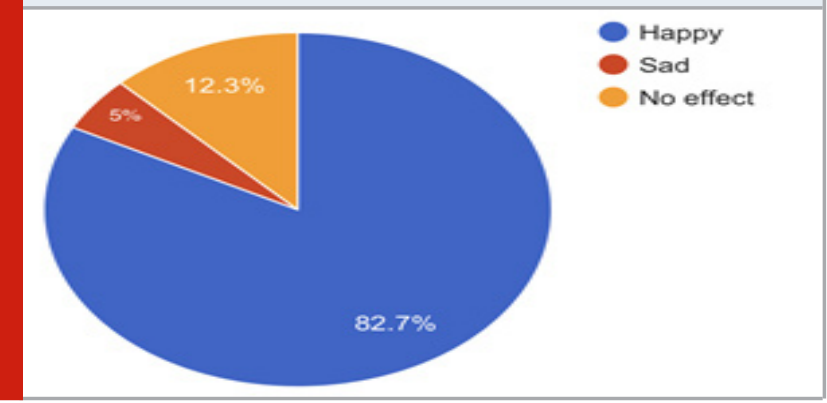

Figure 14: Pie chart depicts percentage distribution of responses on whether the participants get cheerful on seeing their favourite colour. 80.3\% say yes (blue) and $19.7 \%$ say no (red).

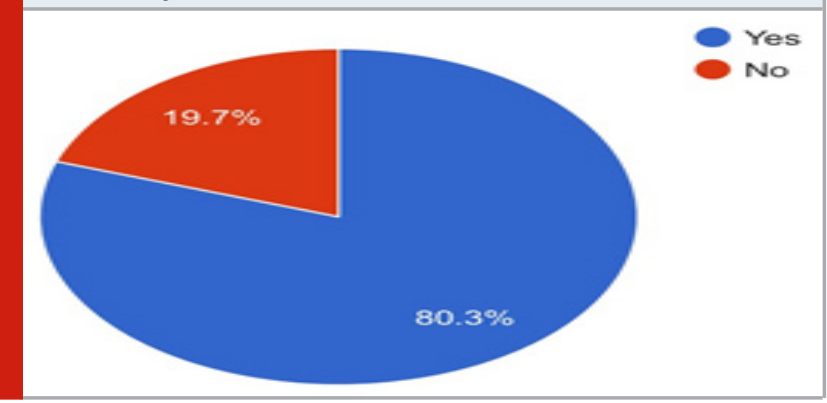

Figure 15: Pie chart depicts percentage distribution of responses on whether the participants are aware that various colours affect moods in different situations. 77.3\% say yes (blue) and 22.7\% say no (red).

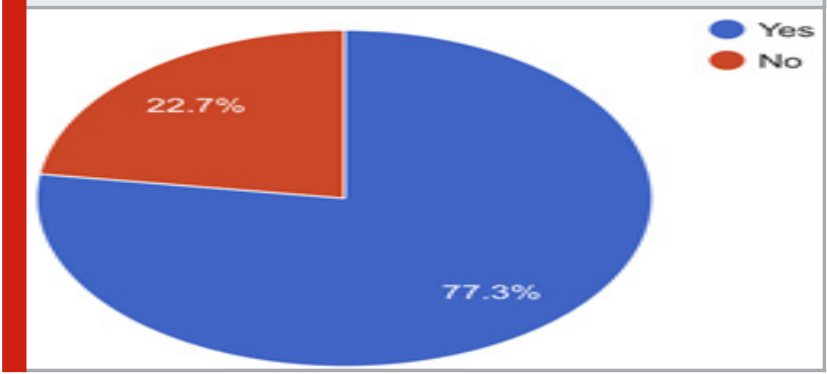

Figure 16: Pie chart depicts percentage distribution of responses on the colour that participants wear when they are happy. 55\% say any colour (blue) and 45\% say favourite colour (red).

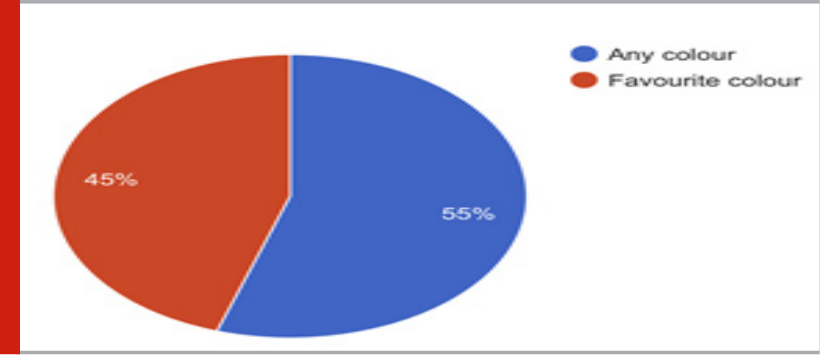


Figure 17: Pie chart depicts percentage distribution of responses on whether the participants are aware that different colours denote different things. 70.1\% say yes (blue) and 29.9\% say no (red).

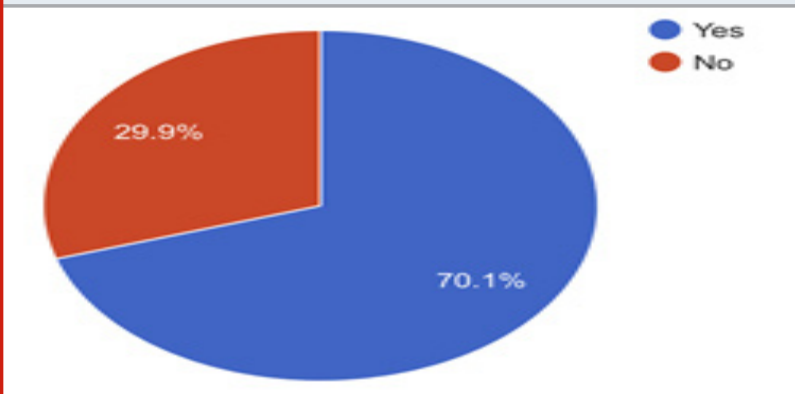

Figure 18: Pie chart depicts percentage distribution of responses on whether the participants have a habit of wearing specific colours on specific days. 30.3\% say yes (blue) and 69.7\% say no (red).

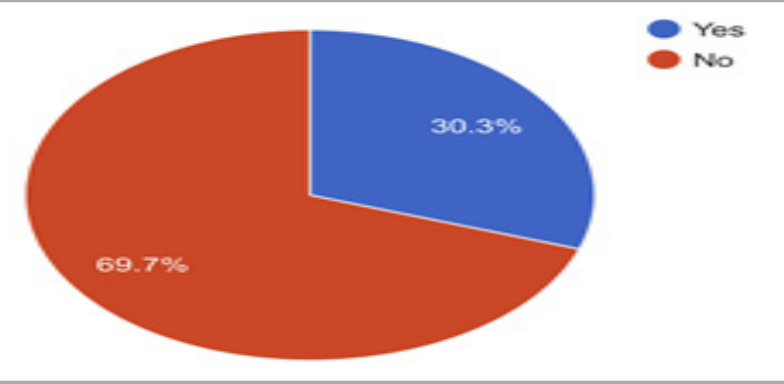

Figure 19: Pie chart depicts percentage distribution of responses on whether daily activities of participants are improved upon wearing their favourite colour. 53.4\% say yes (blue) and $46.6 \%$ say no (red).

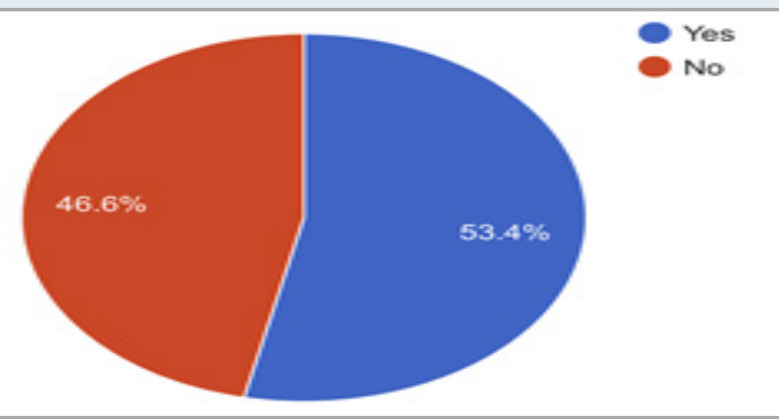

Figure 20: Pie chart depicts percentage distribution of responses of opinion in relation to the happiest colour. $51.1 \%$ say blue (blue), $7.9 \%$ say orange (red), $26.4 \%$ say white (orange) and 14.6\% say yellow (green)

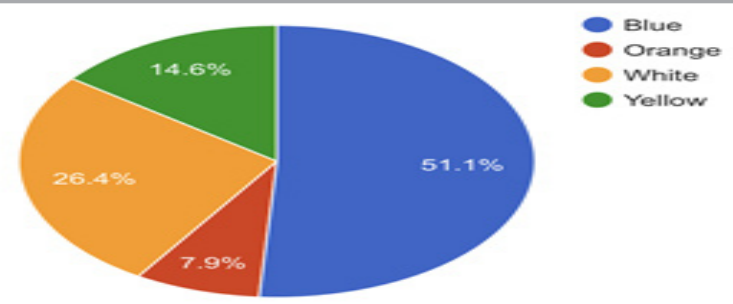

From fig20, it is seen that 51.5\% of the population think that blue is the happiest colour in the world and $26.4 \%$ think that white is the happiest colour,also 26 students think yellow and 14 students think orange is the happiest colour in the world. From fig21, it is found that colour had an impact on $63.1 \%$ of the population and $36.9 \%$ did not find any impact.From fig 22, it is studied that blue is the colour that brings serenity,calmness and relaxation to $57.7 \%$ of the population,the next majority think that it is black.

Figure 21: Pie chart depicts percentage distribution of responses on whether the participants are affected by wearing their favourite colour. 63.1\% say yes (blue) and $36.9 \%$ say no (red).

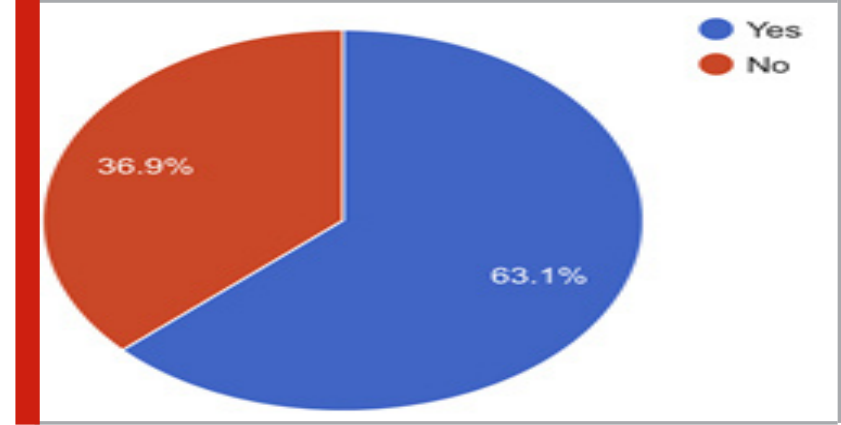

Figure 22: Pie chart depicts percentage distribution of responses on opinion of the colour that keeps them relaxed. $57.7 \%$ say blue (blue), 22.3\% say black (red), 10.3\% say orange (orange) and 9.7\% say purple (green).

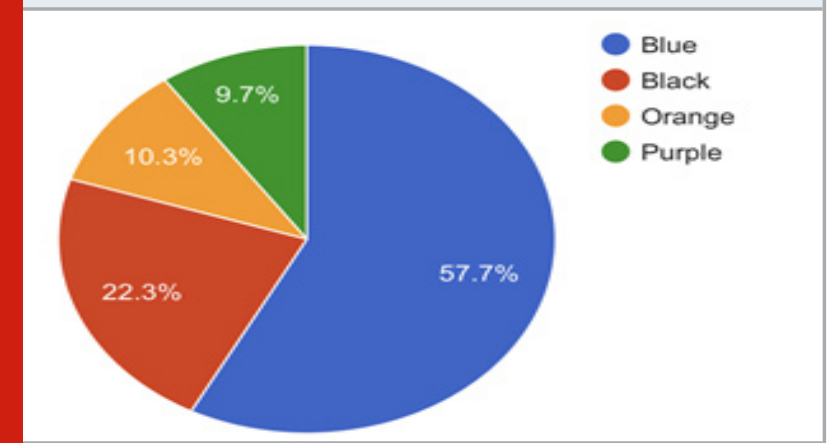

\section{CONCLUSION}

From the study it may be concluded that colour affects mood of an individual as colour is a powerful communication tool and can influence the psychological and physiological reactions.Individuals encounter a kaleidoscope of color in navigating daily life. Surprisingly, almost nothing is known at present regard- ing how the different colors that people perceive impact their effect, cognition, and behavior. In future this study can be used to design or construct various places to provide a pleasant and comfortable environment to the students. Even a counselling room needs to have certain colour codes to carry out the procedure successfully. 


\section{ACKNOWLEDGEMENTS}

The authors extend gratitude to Saveetha Dental college for rendering full support to complete this study.

Conflict of Interest: No conflict of interest declared.

\section{REFERENCES}

Adams, F. M. and Osgood, C. E. (1973) 'A Cross-Cultural

Study of the Affective Meanings of Color', Journal of cross-cultural psychology. SAGE Publications Inc, 4(2), pp. 135-156.

Cherry, K. (no date) Can Color Affect Your Mood and Behavior?, Verywell Mind. Available at: https:// www.verywellmind.com/color-psychology-2795824 (Accessed: 29 June 2020).

Frank, M. G. and Gilovich, T. (1988) 'The dark side of self- and social perception: black uniforms and aggression in professional sports', Journal of personality and social psychology. psycnet.apa.org, 54(1), pp. 74-85.

Kumar, S., Sterkenburg, J. and Diekfuss, J. (no date) [No title]. researchgate.net. Available at: https:// www.researchgate.net/profile/Jed_ Diekfuss/publication/258884762_Color_effects_ on_students'_emotions_and_task_performance_ in_a_web-based_learning_management_system/ links/0a85e531338141b933000000.pdf (Accessed: 29 June 2020).

Kurt, S. and Osueke, K. K. (2014) 'The Effects of Color on the Moods of College Students', SAGE Open. SAGE Publications, 4(1), p. 2158244014525423.

Kwallek, N., Lewis, C. M. and Robbins, A. S. (1988) 'Effects of Office Interior Color on Workers' Mood and Productivity', Perceptual and motor skills. SAGE Publications Inc, 66(1), pp. 123-128.

Labrecque, L. I. and Milne, G. R. (2012) 'Exciting red and competent blue: the importance of color in marketing', Journal of the Academy of Marketing Science. Springer, 40(5), pp. 711-727.

Spence, I. et al. (2006) 'How color enhances visual memory for natural scenes', Psychological science. journals.sagepub.com, 17(1), pp. 1-6. 